\title{
New data on the distribution of the endangered dragonflies Oxygastra curtisii (Dale, 1834), Somatochlora meridionalis (Vander Linden, 1825) and S. flavomaculata Nielsen, 1935 in central-southern Italy (Odonata Cordulidae)
}

\author{
Andrea Corso ${ }^{*}$, Ottavio Janni ${ }^{2}$, Carlo Fracasso ${ }^{3}$,Alessandro Biscaccianti ${ }^{4}$ \& Lorenzo De Lisio ${ }^{5}$ \\ ${ }^{1}$ Via Camastra 10, 96100 Siracusa, Italy; email: zoologywp@gmail.com \\ ${ }^{2}$ Via G.G. D’Amore 21, 81016 Piedimonte Matese, Caserta, Italy; email: coeligena@hotmail.com \\ ${ }^{3}$ Via di Sopra 19, 86018 Toro, Italy \\ ${ }^{4}$ Via Simeto 12, 00198 Roma, Italy \\ ${ }^{5}$ P.zza V. Cuoco 2, 86100 Campobasso, Italy; email: lorenzodelisio@gmail.com \\ ${ }^{*}$ Corresponding author
}

\begin{abstract}
New data on distribution in central-southern Italy of three species of dragonflies (Odonata Cordulidae) are here reported: Oxygastra curtisii (Dale, 1834), Somatochlora meridionalis Nielsen, 1935 and S. flavomaculata (Vander Linden, 1825). The first one it is included in Annex II of Habitat directive of the Europe. For S. curtisi we reports for the first time its presence in Abruzzo and Molise regions, while for meridionalis we report the national south most known sites, while for flavomaculata a range extension of more than $200 \mathrm{~km}$ south.
\end{abstract}

KEY WORDS Dragonflies distribution; Central-South Italy; new records.

Received 13.01.2019; accepted 02.07.2019; published online 18.08.2019.

\section{INTRODUCTION}

Notwithstanding the recent publication of a distribution atlas of Italian dragonflies (Riservato et al., 2014), a European atlas (Boudot \& Kalkman, 2015) and several regional works for central and southern Italy (Grandi, 1957; D'Antonio, 1985, 1994a,b, 1995, 1996; Carchini \& Rota, 1986; Buckwald, 1994; Terzani, 2004), knowledge about the odonates of Campania, Molise and Abruzzo still remains scarce, fragmentary and incomplete. In the last decade, we have covered extensively, although not yet completely, the aforementioned regions, mainly for ornithological research but also for the study of the odonates. $\mathrm{Nu}$ merous and interesting discoveries have rewarded our monitoring, which will gradually converge in various publications and in the drafting of regional check-lists.

In this brief note, for the moment, we want to make known the data concerning three localized and poorly diffused species in Italy, for which the knowledge is still fragmentary and whose distribution area is certainly susceptible to expansion. The species here concisely treated are: Oxygastra curtisii (Dale, 1834), Somatochlora meridionalis Nielsen, 1935 and S. flavomaculata (Vander Linden, 1825). These species were already discussed, as regards for Campania alone, by Janni et al. (2013). In this note, we provide a more comprehensive picture for Campania region and unpublished data for Molise and Abruzzo. 


\section{MATERIAL AND METHODS}

From 2005 to 2017, we have monitored numerous sites considered suitable for the presence of odonates in Campania and Molise, while as regards Abruzzo, we have been able to investigate, in spring-summer 2013 and 2017, only a few areas, and mainly the Majella massif and surrounding areas thanks to a study financed by the National Park of Majella. From April to October we made targeted excursions, in suitable habitats, equipped with camera and entomological nets. The specimens observed, were, when possible, captured to carry out photographic documentation; being rare species and, in the case of the Oxygastra, protected, they were released immediately after. The coordinates were recorded using Lat/Long as a reference system. Cartographic processing was done using QGIS 2.14 Essen. A distribution map is provided indicating the detection points (Figs. 1,2). We also recorded the environmental characteristics of the areas where the species were observed. When possible, we also recorded the number of individuals observed or estimated.

ABBREVIATIONS: ex./exx.: specimen/specimens.

\section{RESULTS}

Figure 1 and figure 2 show all the sites where the

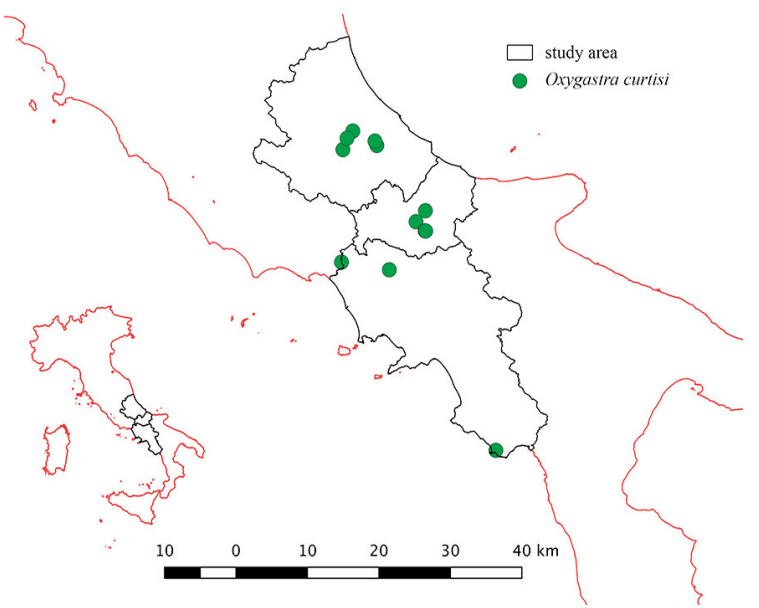

Fig.1 - Distribution of Oxygastra curtisi in Abruzzo, Molise and Campania (Italy) with regional boundaries and the sampled stations. three species examined here were found. Following we report comments and details species by species:

\section{Oxygastra curtisii (Dale, 1834)}

EXAMINED MATERIAL. New data. Abruzzo: 2 males observed in flight on 25.VII.2013 near Pennapiedimonte (Chieti) $\left(42^{\circ} 8^{\prime} 50.85^{\prime \prime} \mathrm{N}, 14^{\circ}\right.$ 11 '50.31" E; 452 meters asl) and 1 female in proximity of Bocca di Valle (Chieti) (42 ${ }^{\circ} 10^{\prime} 38.24$ ” N, $14^{\circ} 10^{\prime} 41.87^{\prime \prime} \mathrm{E} ; 650$ meters above sea level) (A. Corso, personal data). During a monitoring carried out in 2017, the species was recorded in three sites: 1) Sorgente Sulfurea, Tocco da Casauria (Pescara province), slopes of Monte Rotondo (42 $11^{\prime} 39.10^{\prime \prime}$ N, 13'54'39.37' E; 449 meters asl) - 5 males observed on 17.VII.2017 and 3 females on 18.VII.2017; 2) River Orta between Piano d'Orta (Pescara) and Bolognano $\left(42^{\circ} 14^{\prime} 39.98^{\prime \prime} \mathrm{N}\right.$, 135' $57.54^{\prime \prime} \mathrm{E}$; 144 meters asl) - 2 males observed on 16.VII.2017; 3) Piana del Sagittario, near Sulmona (42 6'57.03" N, 1352'23.14' E) - 2 females observed on 18.VII.2017. Molise: first regional report made at the centre of the town of Campobasso (4133’32.79” N; 1440'1.39” E; 680 meters asl), when a teneral ex. was photographed laid on the wheel of a car on 29.VI.2011 (photo by C. Fracasso, det. A. Corso). In July 2011, a mature male was observed in flight always in the centre of Campobasso (4133'36.69” N, 1439'41.70" E; 703 meters asl) (A. Corso, L. De Lisio). Since then, we have ob-

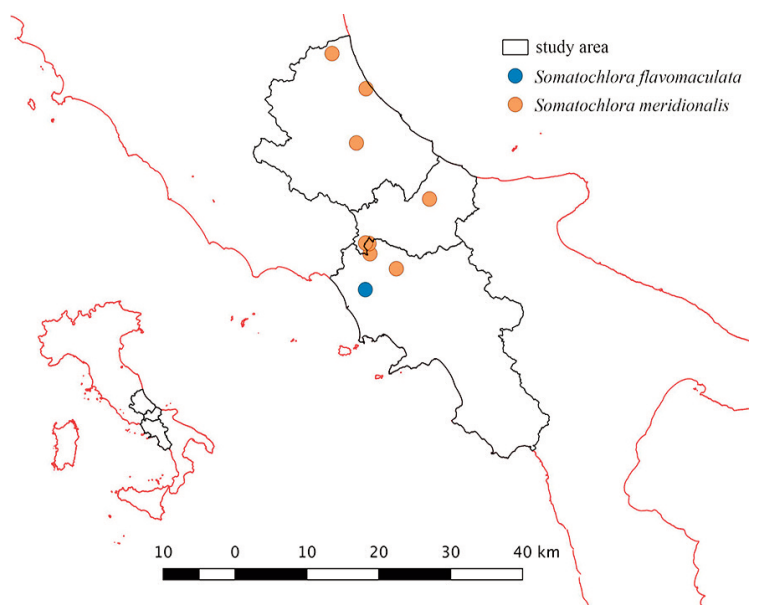

Figure 2. Distribution of Somathoclora meridionalis and S. flavomaculata, in Abruzzo, Molise and Campania (Italy) with the regional boundaries and sampled stations. 
tained regular observations on several sites: for example, numerous exx. observed along the River Biferno, in particular at the height of the municipality of Petrella Trifernina (Campobasso) $\left(41^{\circ} 41^{\prime} 55.75^{\prime \prime} \mathrm{N}, 14^{\circ} 39^{\prime} 48.84^{\prime \prime} \mathrm{E}\right.$; 275 meters asl) where the species is regularly recorded, with up to a $>15$ exx. observed here eg on 27.VI.2016, but also between Cerreto and Castropignano (Campobasso) (4137'22.38' N, 14³4'28.07' E; 390 meters asl) (Figs. 3, 4). Campania: first regional reports reported by Carchini \& Rota (1986) with 2 males at F. Mingardo, Marina di Camerota (Salerno) on 14-17.VII.1983. For the province of Caserta, it was known only for the River Garigliano (D'Antonio, 1995). New data: starting from May 2005, this species has been observed regularly and with a consistent number of exx. along a stretch of at least 20 $\mathrm{km}$ of the middle River Volturno, between the municipalities of Presenzano (Caserta) upstream and Gioia Sannitica (Caserta) further downstream (Janni et al., 2013). These are the first reports of this species for the Volturno area (Janni et al., 2013). The population present along the Volturno, is therefore of great protectionist interest, not only for its numerical consistency - the species seems to be common along the whole stretch of the river- but also for the fact that the species it is extremely localized in southern Italy, and the population of Caserta is almost certainly the main population to date. Further investigations are therefore desirable to determine more accurately the consistency of this population.

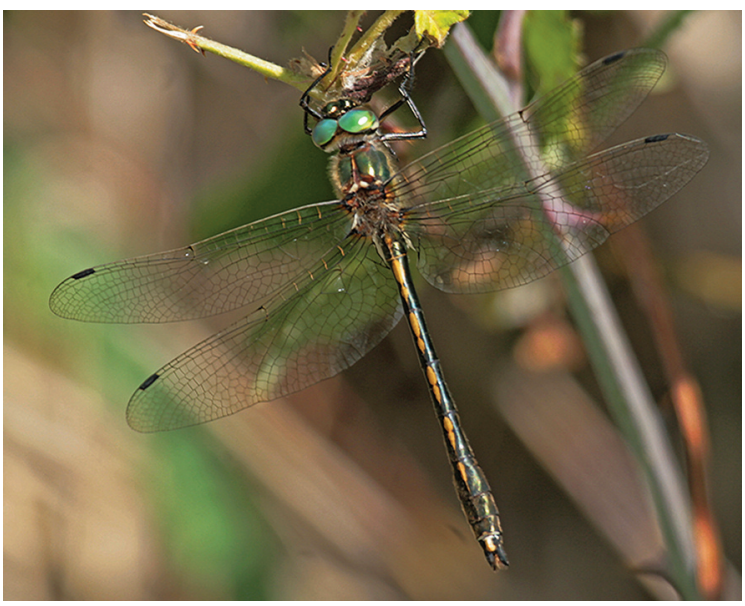

Figure 3. Oxygastra curtisii, male mature, 21st June 2015, River Biferno (Campobasso, Molise, Central Italy) (photo by C. Fracasso).
Distribution. Distributed in Western Europe from France (where is most widespread) to Portugal and Spain, it is also found in Morocco (chiefly in the northern, more humid, part of the country) (Boudot \& Kalkman, 2015). In Italy, it has a scatter distribution over the north-western regions, chiefly Liguria and Lombardia, with localized populations found also in central Italy, mostly in Tuscany and Lazio (Riservato et al., 2014). Formerly considered absent from north to central-eastern and southern regions, it was recently recorded in Abruzzo and Molise (this study).

REMARKs. Not reported for Abruzzo and Molise by D'Antonio (1994b) as well as in the two main and most recent atlases of distributions of the odonates in Italy (Riservato et al., 2014) and Europe (Boudot \& Kalkman, 2015). These works mention the adjacent Campania, Lazio and Marche as regions where the species was reported both historically and in recent years (D'Andrea, 1994; Dell'Anna \& Ketmajer 1997; Boudot \& Kalkman, 2015). In the last ten years, we found the species locally abundant in Lazio, where for example it is particularly easy to observe along the course of the Trentino Treia Valley, between Waterfalls of Monte Gelato, Mazzano Romano and Calcata (Viterbo) (A. Corso, O. Janni \& V. Penna, ined.). In centralnorthern Campania, it resulted also rather widespread and locally abundant. Further, we recorded it for the first time in Molise and Abruzzo (Majella massif).

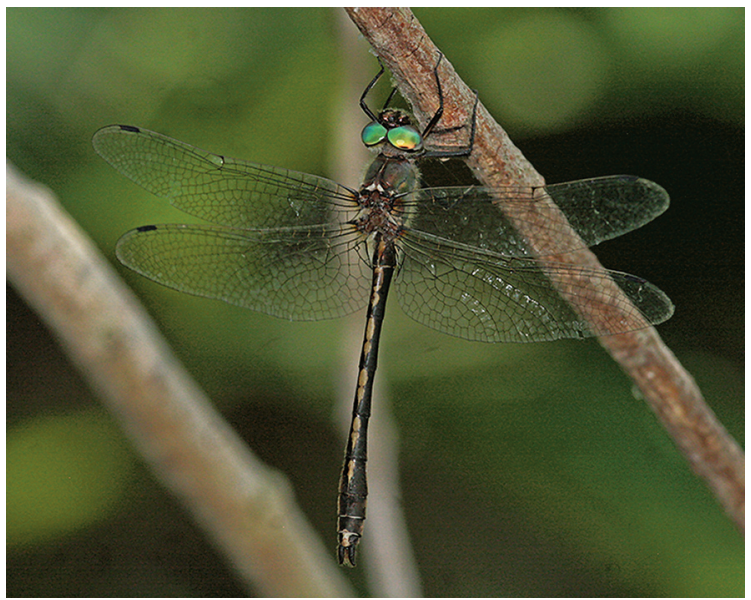

Figure 4. Oxygastra curtisii, male mature, 19th July 2015, Biferno (Campobasso, Molise, Central Italy) (photo by C. Fracasso). 


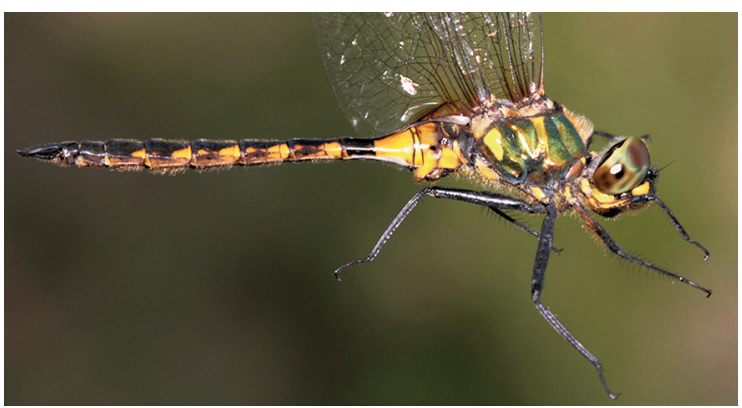

Figure 5. Somatoclhora flavomaculata, male mature, 26.VI.2012, Sant'Andrea del Pizzone, AFV “Mazzoni”, loc. Caserio Reale (Francolise, Campania) (photo by A. Corso).

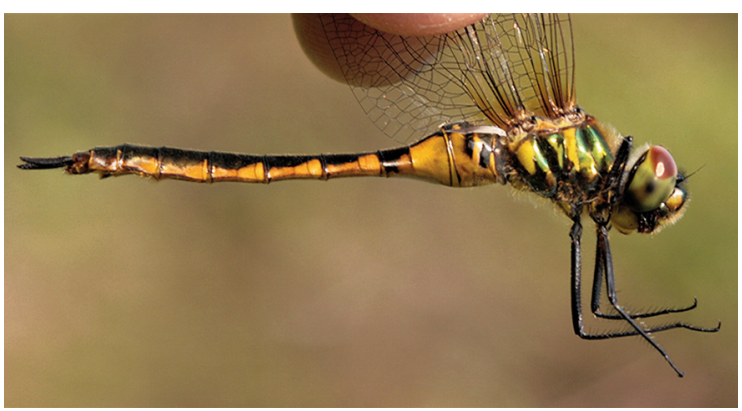

Figure 6. Somatochlora flavomaculata, female, 26.VI.2012, Sant'Andrea del Pizzone, AFV "Mazzoni", loc. Caserio Reale (Francolise, Campania) (photo by A. Corso).

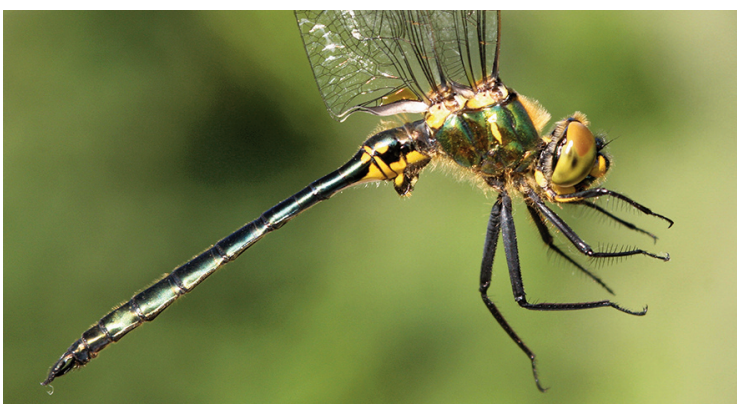

Figure 7. Somatochlora meridionalis, 1935, male mature, 27.VI.2012, San Silvestro, loc. Totari (Alife, Campania) (photo by A. Corso).

Somatochlora flavomaculata (Vander Linden, 1825)

EXAMINED MATERIAL. New data Campania: during our studies in this region, we found the species for the first time in 2011 in the province of Caserta
(Janni et al., 2013), while we have not been able, at present, to gather evidence of the its presence in the other two regions examined here. Specifically, a small population - no more than 5 exx. (both sexes) observed simultaneously - was discovered on 14.VI.2011 near Sant'Andrea del Pizzone, AFV "Mazzoni", Loc. Caserio Reale (Francolise, Caserta) (41ㅇ'58.08" N, $14^{\circ} 5^{\prime} 40.86^{\prime \prime}$ E, 10 meters asl), in the Volturno plain. The presence of this population has been confirmed and documented photographically in June 2012 and 2016, when a few exemplars were again recorded (Figs. 5, 6). The habitat in which this population was found consists of an agricultural mosaic (mainly fodder) crossed by small irrigation canals with thick vegetation and very little open water.

Distribution. Distributed through centralnorth-western Europe, from France and Germany to the Scandinavian Peninsula, all the way to the Russian federation, it is scarcer to the south with scatter and localized population down to Turkey (Boudot \& Kalkman, 2015). In Italy rather well diffused all over the Northern regions, with very isolated small nuclei found in Puglia, at the border between Basilicata and Calabria and in Campania (Riservato et al. 2014).

REMARKS. In southern Italy, this species is extremely localized with small populations in Puglia and Basilicata (Carchini \& Rota, 1986; D'Antonio, 1994; Riservato et al., 2014). Not reported by Riservato et al. (2014) and by Boudot \& Kalkman (2015) for Molise and Abruzzo, they report a single report for Campania. Therefore, the record here reported constitutes not only the first mention of the species in Campania, but also an extension of its Italy distribution area of about $200 \mathrm{~km}$ to the south. Further investigations are needed to verify the presence of this species elsewhere in the region or in Molise.

\section{Somatochlora meridionalis Nielsen, 1935}

EXAMINED MATERIAL. New data. One record from the Majella National Park, 1 male near Caramanico Terme (Chieti), along the Orta River valley, on 25.VII.2013 (429'27.93” N, 1359'44.76” E; 437 meters asl) (A. Corso, personal data). Not found in further research in 2017, it remains to be seen the real consistence of the populations in 
Abruzzo and their distribution. Observed in numerous stations in Lazio (Riservato et al., 2014; pers. obs.) along the regional borders with Abruzzo, it is certainly more widespread compared to what what current data show. Molise: in this region, we have observed the species for the first time on 25.VI.2011 at Torrente Vallone Grande di Civitacampomarano (Campobasso) (4146'33.75” N, $14^{\circ} 41^{\prime} 30.48^{\prime \prime} \mathrm{E} ; 380$ meters asl), when we recorded 4 exx. (A. Corso, L. De Lisio and C. Fracasso, personal data). In the same site, 2 exx. observed on 02.VI.2016 (C. Fracasso, personal data). We have no further data. Campania: a single report for this region was known from literature, referring to 1 male collected on 12.VII.1993 at Capriati a Volturno, River Sava (affluent of River Volturno) (Caserta) $\left(41^{\circ} 28^{\prime} 2.03\right.$ ” N, 147'29.55” E; ca 320 meters asl) (Utzeri et al., 1998, 1999), contrariwise to what reported by Janni et al. (2013) that do not mention this data. Since June 2009, the species was found in many localities in the Caserta area: WWF Oasi Le Mortine (Capriati al Volturno, Caserta) (4128'11.71" N, 145'31.04" E; 170 meters m asl); Palombiscio (Pratella, Caserta) (41 ${ }^{\circ} 23^{\prime} 47.76^{\prime \prime} \mathrm{N}$, $14^{\circ} 8^{\prime} 4.86^{\prime \prime}$ E; ca 200 meters asl); San Silvestro, Loc. Totari (Alife, Caserta) $\left(41^{\circ} 17^{\prime} 43.01^{\prime \prime} \mathrm{N}\right.$, $14^{\circ} 22^{\prime} 58.94^{\prime \prime} \mathrm{E}, 100$ meters asl). At the latter site, the species is common, with for example more than 30 exx. observed on 25.VI.2012 (O. Janni \& A. Corso) (Fig. 7). These records are the southernmost for Italy.

DisTRIBUTION. Distributed through south-eastern Europe, from Austria to Western Turkey, well diffused in Albania, Greece, Serbia, Croatia, Northern Macedonia, and so on, the northern limit of its range is still unclear (Boudot \& Kalkman, 2015). In Italy it has a discontinuous distribution, with scatter and localized populations in Liguria, Piemonte, then to the eastern part in Friuli Venezia-Giulia and more widespread nuclei all over the central regions as Tuscany, Lazio, Umbria and Marche (Riservato, et al., 2014). In Southern Italy only found in single stations in Puglia and Campania (this study).

Remarks. Not reported for Abruzzo by Utzeri et al. (1999). Riservato et al. (2014) report two stations without further details. For Molise, D'Antonio (1994b) does not report the species while a single station between Molise and Campania is shown in the distribution map in Riservato et al. (2014).
Utzeri et al. $(1998,1999)$ report an indication for Campania (see below). Specifications Abruzzo: the first known data for Abruzzo, reported in Riservato et al. (2014) are in details: 1) some exx. observed at T. Piomba, Città di Sant'Angelo (Pescara), on 5.VII.2012 (42 $531^{\prime} 52,77^{\prime \prime} \mathrm{N}$, $14^{\circ} 08^{\prime} 11,80^{\prime \prime}$ E, 35 meters asl) (A. Festi, com. pers.); 2) some exx. observed at "Il Goscio di Floriano", Campli (Teramo), on 7.VII.2012 $\left(42^{\circ} 77^{\prime} 02,08^{\prime \prime} \mathrm{N}, 13^{\circ} 75^{\prime} 17,61^{\prime \prime} \mathrm{E}, 35\right.$ meters asl) (F. Landi, com. pers.).

\section{ACKNOLEDGMENTS}

We wish to thanks, for the help in the field: Verena Penna (Roma, Italy), Giovanni Capobianco (Caserta, Italy), Raimondo Finati (Caserta, Italy), Roberto Casalini (Roma, Italy), Andrea Pulvirenti (Roma, Italy), Mauro Grano (Roma, Italy), Cristina Cattaneo (Roma, Italy), Diego Reggianti (Roma, Italy), Claudia Ferralis (Roma, Italy). For the data and the help with references, we warmly thanks our friends: Carlo Utzeri (Roma, Italy), Alex Festi and Federcio Landi, as well the whole team Odonata.it. The Majella National Park Authority (Abruzzo) and in particular Dr. Pino Marcantonio (Sulmona, Italy), and the Aspromonte National Park Authority (Reggio Calabria, Italy) and in particular Dr. Sergio Tralongo (Reggio Calabria, Italy) and Dr. Antonino Siclari (Reggio Calabria, Italy) are sincerely thanked for the funds for the researches in their respective parks as part of studies to monitor and protect odonate species in the Habitats Directive. The Leica Sport Optics is thanked, in particular, Dr. Francesco Corrà (Varese, Italy) and Nanette Roland (Berlin, Germany) for providing the optical instruments used by A. Corso during this study.

\section{REFERENCES}

Boudot J.P. \& Kalkman V. (Eds.), 2015. Atlas of the European dragonflies and damselflies. KNNV Publishing, The Netherlands, 384 pp.

Buchwald R., 1994. Vegetazione e odonatofauna negli ambienti acquatici dell'Italia Centrale. Braun-Blanquetia, 11: 1 .

Carchini G. \& Rota E., 1986. Attuali conoscenze sulla 
distribuzione degli odonati dell'Italia meridionale. Biogeographia, 10: 629-684.

D’Andrea M., 1994. Segnalazioni faunistiche Italiane. N² 247 Oxygastra curtisii (Dale, 184 ) (Odonata, Corduliidae). Bollettino della Società entomologica italiana, 126: 76.

Dell'Anna L. \& Ketmaier V., 1997. Odonata (Insecta). In: Osella B.G., Biondi M., Di Marco C. \& Riti M., (a cura di), Ricerche sulla Valle Peligna (Italia Centrale, Abruzzo), Vol. I, 143-153.

D'Antonio C., 1985. Attuali conoscenze sul popolamento odonatologico della Campania (III contributo alla conoscenza degli Odonati). Bollettino della Società dei naturalisti in Napoli, 94: 187-201.

D'Antonio C., 1994. Gli Odonati della Basilicata (Odonata). Bollettino della Società entomologica italiana, 126: 121-133.

D'Antonio C., 1994b. Primi dati sugli Odonati del Molise (Odonata). Bollettino della Società entomologica italiana, Genova 12: 187-190.

D’Antonio C., 1995. Gli Odonati della Campania (Odonata). Bollettino della Società entomologica italiana, 127: 103-116.

D’Antonio C., 1996. Gli Odonati della Calabria (Odonata). Bollettino della Società entomologica italiana, 128: 3-16.

Grandi G., 1957. Campagna di ricerche dell'Istituto di Entomologia dell'Università di Bologna nel Parco
Nazionale d'Abruzzo. I. Sguardo d'insieme ai resultati della Campagna. Bollettino dell'Istituto di Entomologia dell'Università di Bologna, 2: 133.

Janni O., Corso A. \& Capobianco G., 2013. Nuove scoperte odonatologiche dalla provincia di Caserta. VI Convegno Nazionale (Odonata.it) "Le Libellule in Italia" (Trevi): 32. http://ardeaonlus.it/wp-content/uploads/2013/04/POSTER-JanniCapobainco.pdf

Terzani F., 2004. Odonati del Molise (Italy meridionale): nuovi dati (Odonata). Onychium, 1: 1-2.

Riservato E., Festi A., Fabbri R., Grieco C., Hardersen S., La Porta G., Landi F., Siesa M.E. \& Utzeri C., 2014. Odonata. Atlante delle libellule Italiane - preliminare. Società Italiana per lo Studio e la Conservazione delle Libellule. Edizioni Belvedere, Latina, 224 pp.

Utzeri C., Giardini L., Baldi A. \& Carchini G., 1998. Segnalazioni faunistiche Italiane: Somatochlora meridionalis Nielsen, 1935 (Odonata Codruliidae). Bollettino della Società entomologica italiana, 130: 77.

Utzeri C., Di Giovanni M.V., Goretti E., Terzani F., Speziale A., Mei M., Santolamazza Carbone S. \& Cordero A., 1999. Updated information on the distribution of Somatochlora meridionalis Nielsen, 1935, in central Italy (Anisoptera: Corduliidae). Notulae odonatologicae, 5: 43. 